\title{
Copy number variation of IL17RA gene and its association with the ankylosing spondylitis risk in Iranian patients: a case- control study
}

Hamideh Aghaei ${ }^{1,2}$, Elham Farhadi ${ }^{2,3}$, Maryam Akhtari $^{2}$, Sara Shahba ${ }^{2}$, Shayan Mostafaei ${ }^{4}$, Ahmadreza Jamshidi ${ }^{2}$, Shiva Poursani ${ }^{2}$, Mahdi Mahmoudi ${ }^{2,3^{*}}$ (i) and Mohammad Hossein Nicknam ${ }^{1,5^{*}}$

\begin{abstract}
Background: Ankylosing spondylitis (AS) is considered as a subtype of spondyloarthritis (SpA) that mainly leads to fatigue, stiffness, spinal ankylosis, and impaired physical functions with reduced quality of life. Interleukin (IL)-17A provokes additional inflammatory mediators and recruits immune cells to the inflamed site. IL17 expression increased in various inflammatory disorders including psoriasis, rheumatoid arthritis, multiple sclerosis, crohn's disease, and ankylosing spondylitis. The current study aimed to evaluate the association of IL17RA copy number changes with the susceptibility to AS and their correlation to IL17RA expression in Iranian population.

Methods: IL17RA copy number genotyping assessments were carried out in 455 AS patients and 450 healthy controls, using custom TaqMan CNV assays. TaqMan primers and probe were located in Chr.22:17109553 based on pre-designed IL17RA Copy Number Assay ID, Hs02339506_cn. mRNA expression of IL17RA was also measured by SYBR Green real-time polymerase chain reaction (PCR).

Results: A IL17RA copy number loss ( $<2)$ was associated with AS compared to 2 copies as reference (OR:2.18, 95\% Cl: (1.38-3.44), P-value < 0.001) and increased the risk of AS. IL17RA mRNA expression showed a significant increase in peripheral blood mononuclear cells (PBMCs) of all AS individuals than controls. The mRNA expression level of 2 copies was significantly higher in AS patients.

Conclusions: Our findings revealed that a low copy number of IL17RA might confer a susceptibility risk to AS. However, it is probably not directly involved in the regulation of IL17RA mRNA expression. Epigenetic mechanisms like DNA methylation, post-transcriptional, and -translational modifications that regulate the expression of the genes may contribute in upregulation of IL17RA mRNA expression in the loss of gene copy number condition.
\end{abstract}

Keywords: Ankylosing spondylitis, Autoimmunity, Copy number variations, Gene expression, IL17RA

\footnotetext{
* Correspondence: mahmoudim@tums.ac.ir; mhnicknam@sina.tums.ac.ir

${ }^{2}$ Rheumatology Research Center, Tehran University of Medical Sciences, Tehran, Iran

'Department of Immunology, School of Medicine, Tehran University of Medical Sciences, Tehran, Iran

Full list of author information is available at the end of the article
}

(c) The Author(s). 2020 Open Access This article is licensed under a Creative Commons Attribution 4.0 International License, which permits use, sharing, adaptation, distribution and reproduction in any medium or format, as long as you give appropriate credit to the original author(s) and the source, provide a link to the Creative Commons licence, and indicate if changes were made. The images or other third party material in this article are included in the article's Creative Commons licence, unless indicated otherwise in a credit line to the material. If material is not included in the article's Creative Commons licence and your intended use is not permitted by statutory regulation or exceeds the permitted use, you will need to obtain permission directly from the copyright holder. To view a copy of this licence, visit http://creativecommons.org/licenses/by/4.0/. The Creative Commons Public Domain Dedication waiver (http://creativecommons.org/publicdomain/zero/1.0/) applies to the data made available in this article, unless otherwise stated in a credit line to the data. 


\section{Background}

Ankylosing spondylitis (AS) is considered as a subtype of spondyloarthritis $(\mathrm{SpA})$ that mainly leads to fatigue, stiffness, spinal ankylosis, and impaired physical functions with reduced quality of life (QoL) $[1,2]$. In spite of various investigations concerning AS pathogenesis, the exact cause, and underlying mechanisms are still less clear [3-6]. However, according to the numerous studies taken in the past decades, genetic background and immunological dysfunctions are regarded as pivotal bases of the disease [7-10].

Interleukin (IL)-17A, the first known subset of the IL17 family, primarily secreted from multiple cell types including, $\gamma \delta \mathrm{T}$ cells, natural killer T cells (NKT cells), group 3 Innate lymphoid cells (ILC3s) and particularly Th17 [11, 12]. This pro-inflammatory cytokine provokes additional inflammatory mediators and recruits immune cells to the inflamed tissue. IL-17 mostly leads to production of several chemical messengers such as proinflammatory cytokines (IL-6, IL-8, TNF- $\alpha$, IL-1 $\beta$ ), granulocyte attracting chemokines (granulocyte-colony stimulating factor (G-CSF), granulocyte monocyte-colony stimulating factor (GM-CSF), CCL2 (MCP-1), CXCL2 (MIP-2), CXCL5, CCL20 (MIP3A)), matrix metalloproteinases (MMP1, MMP3, MMP9, and MMP13) and anti-microbial peptides [13-16].

Taken together, the aberrant IL-17 signaling pathway contribute to developing several autoimmune disorders [12]. It is clearly stated that the excessive production of IL-17 can lead to various inflammatory diseases such as psoriasis, rheumatoid arthritis (RA), AS, multiple sclerosis (MS) and crohn's disease (CD) [17-19]. Accordingly, prior investigations have found the increased concentration of IL-17 in the serum of AS patients and the frequency of Th17 cells also elevated in peripheral blood and synovial fluids of AS patients [20, 21].

The IL-17 activation is provided after binding to receptor site on target cells. As previously reported, IL-17 binds to a complex of IL-17RA and IL-17RC to induce responses via its unique signaling pathway [22]. IL-17RA (also termed as IL-17R), is the first member of IL-17R superfamily (IL-17RA-IL-17RE) which recognizes both IL-17A and IL-17F, but have more affinity to IL-17A than IL-17F about 100 fold greater [23]. This family is distinctive from other known cytokine receptor families with its particular structure and signaling cascade through ACT1 (NF-kB activator 1) adaptor molecule [24]. IL17RA showed expression on the variety of tissues, and cell types, particularly in hematopoietic cells and upon stimulation with its ligand can activate NF- $\mathrm{B}$, a major inflammatory transcription factor [25, 26]. In addition to its capacity to induce unbalanced cytokine production, it can reinforce the effect of other potent cytokines including TNF- $\alpha$ and IL- $1 \beta$, which leads to prolonged inflammatory responses and exacerbate chronic inflammations [27, 28].
To date, there are mysteries in genetic aspects of AS. Recent discoveries have emphasized the substantial role of single nucleotide polymorphisms (SNPs) in AS pathogenesis [29-32]. The newly performed study by VidalCastiñeira et al. assessed the association of IL17RA polymorphisms with AS risk [33]. Besides SNPs, copy number variations (CNVs) are believed to contribute to the etiology of ankylosing spondylitis. They are known as different copies of a specific fragment of DNA created due to deletions or duplications that captured 1 Kilobase to several megabases of the genome [34]. Given that CNVs are harboring $12 \%$ of the human genome, they can strongly affect the expression of genes encoding proteins [35]. CNVs exert their influence on gene expression through gene dosage imbalances in dosage-sensitive genes and cause changes in mRNA and eventually in protein level [36]. In addition to simple gene dosage effect, rearrangements in the gene regulatory elements can also alter gene expression. These rearrangements lead to changes in the interval between genes to regulatory regions. New fused genes can form as a result of rearrangements [37]. Moreover, a growing number of reports underscore the importance of CNVs in some complex diseases such as RA, psoriasis, Crohn's disease, and systemic lupus erythematosus (SLE), autism, schizophrenia, type 1 diabetes (T1D), human immunodeficiency virus (HIV) and cancers [38, 39].

Recently, a genome-wide copy number variation analysis has identified 9 loci as potential candidate CNV regions [40]. Among them, IL17RA has been significantly associated with AS and showed a protective role in susceptibility to AS [40]. To gain more insight into the genetic structure of AS, it would be instrumental in following up initial clues provided by the copy number variation analysis study.

With regards to $I L 17 R A$ expression on immune cells, it seems that changes in the copy number of the gene might influence the gene by altering its expression. However, the contribution of IL17RA gene CNVs in the pathogenesis of AS and its influence on IL17RA gene expression has not been investigated yet. Here, we set out to determine whether ILI7RA copy number variations would predispose individuals to the AS in the Iranian population.

\section{Methods \\ Study populations}

A total of 455 AS patients (85.1\% males) and 450 age-, race and sex-matched healthy controls ( $87.3 \%$ males) were involved. All AS patients were recruited from the rheumatology clinic, Shariati Hospital, Tehran, and met the modified New York diagnostic criteria for AS [41]. All controls had no family history of AS or other autoimmune diseases. More detailed characteristics of enrolled participants are represented in Table 1 . The 
Table 1 Demographic data and clinical features of AS patients and healthy controls recruited in this study

\begin{tabular}{llll}
\hline Characteristics & AS patients & HCs & $\boldsymbol{P}$-value \\
& $\boldsymbol{N}=455(\%)$ & $\boldsymbol{N}=450(\%)$ & \\
\hline Sex (Male) & $387(85.1 \%)$ & $393(87.3 \%)$ & 0.37 \\
Age & $38.10 \pm 10.46$ & $36.60 \pm 8.25$ & 0.86 \\
ESR & $20.28 \pm 20.19$ & $5.84 \pm 6.18$ & $<0.001^{* * *}$ \\
Age symptom & $23.38 \pm 8.43$ & - & NA \\
Age diagnosis & $30.93 \pm 9.45$ & - & NA \\
Disease duration & $14.88 \pm 9.37$ & - & NA \\
NRSBASG & $9.73 \pm 5.36$ & - & NA \\
ASQOL & $7.67 \pm 5.26$ & - & NA \\
BASMI & $4.07 \pm 1.86$ & - & NA \\
BASDAI & $4.72 \pm 2.48$ & - & NA \\
BASFI & $3.82 \pm 2.59$ & - & NA \\
\hline
\end{tabular}

All values are represented as Mean \pm Standard Deviation; NA not applicable, AS ankylosing spondylitis, $H C s$ healthy controls, ESR erythrocyte sedimentation rate, NRS-BASG numerical rating scale-bath AS patient global score, ASQOL ankylosing spondylitis quality of life, $B A S M I$ bath ankylosing spondylitis metrology index, BASDAl bath ankylosing spondylitis disease activity index, $B A S F I$ bath ankylosing spondylitis functional index

* $P<0.05$; ${ }^{*} P<0.01$; ${ }^{* *} P<0.001$

written informed consent was signed by all members of the case and control groups before enrolling in the study. Moreover, this study was approved by ethics committee at the Tehran University of Medical Sciences (Approval ID: IR.TUMS.MEDICINE.REC.1398.696).

\section{Genomic DNA extraction}

The blood sample was taken from participants, and the isolation of peripheral blood mononuclear cells (PBMCs) were done based on Ficoll-Hypaque gradient technique (innotrain, Germany). DNA samples were isolated from PBMCs in standard collection tube with EDTA as anticoagulants using DNSol MidiPrep DNA extraction kit (Roje Technologies Co., Iran). For evaluating the purity of DNA, the absorbance of DNA samples was measured at 260 and $280 \mathrm{~nm}$ using Thermo Scientific/2000C Nanodrop. Pure DNA has an A260/A280 ratio ranges from 1.8-2.0. Extracted DNA from all samples were stored at $-20{ }^{\circ} \mathrm{C}$ until copy number evaluation.

\section{Determination of the IL17RA copy number}

For analysis of IL17RA gene copy number, we used the predesigned TaqMan CNV qPCR assay (Assay ID: Hs02339506_cn), which is purchased from Applied
Biosystems (Foster City, CA, USA) (http://bioinfo. appliedbiosystems.com/genomedatabase/copy-numbervariation.html). IL17RA TaqMan assay includes 2 targetspecific primers and a FAM/MGB dual-labeled probes which are located in Chr.22:17109553 (within exon 13). The genetic structure of IL17RA gene and the position of Hs02339506_cm TaqMan assay containing primer sets and probe illustrated in Fig. 1. Additionally, TaqMan Copy Number Reference Assay (RNase P) includes two primers and VIC/TAMRA labeled probes which used as a standard reference assay recommended by the manufacturer's protocol. Each reaction included $5 \mu \mathrm{l}$ of $2 \times$ TaqMan Genotyping Master Mix, $0.5 \mu \mathrm{l}$ of IL17RA TaqMan copy number assay, $0.5 \mu \mathrm{l}$ of TaqMan Copy Number RNAse P Reference Assay, $2.5 \mu \mathrm{l}$ of water, and $1.5 \mu \mathrm{l}$ of 10 $\mathrm{ng} / \mu \mathrm{l}$ genomic DNA in a $10 \mu \mathrm{l}$ total volume. All samples were run in duplicate in a 96 well plate, and fluorescence signals emitting from reporter dyes (FAM and VIC) were normalized to ROX (passive reference dye). Real-time PCR was done under thermal cycling program comprised of 1 holding stage of $10 \mathrm{~min}$ at $95^{\circ} \mathrm{C}$, followed by 40 cycles in $15 \mathrm{~s}$ at $95^{\circ} \mathrm{C}$ and $60 \mathrm{~s}$ at $60^{\circ} \mathrm{C}$.

Amplification data were analyzed using Applied Biosystems StepOnePlus software (version 2.3), and raw data of CT (threshold cycle) values were imported to CopyCaller ${ }^{\circ}$ Software v2.0 (Applied Biosystems) to calculate the gene copy number in each sample. The comparative $\mathrm{Ct}$ method ( $\Delta \Delta \mathrm{Ct}$ formula) was applied to estimate the relative gene copy number. To grant validity to results, confidence values were higher than $95 \%$, and Z-Score was $<1.75$. Besides, CT of the reference gene was set $<32$, and the SD of $\triangle \mathrm{CT}$ between replicates was less than \pm 0.2 .

\section{mRNA expression of IL17RA}

First, total RNA extraction was implemented from PBMCs of 68 cases and 53 controls with the High Pure RNA isolation kit (Roche, Germany). Total RNA concentration was determined by measuring the absorbance at $260 \mathrm{~nm}$ in Thermo Scientific/2000C Nanodrop. Afterward, reverse transcription (RT) was performed to synthesize cDNA from RNA by the PrimeScript RT reagent Kit (Takara, Japan). Subsequently, relative quantification of mRNA expression was conducted by SYBR Green qPCR on a StepOnePlus Real-time PCR system. Gene expression analysis was carried out with specific primers for IL17RA (Forward primer: 5'-AGTTCCAC

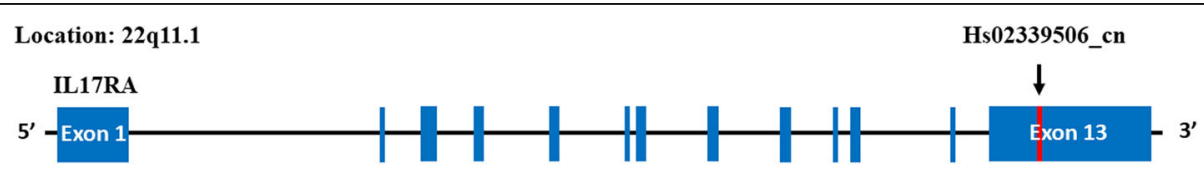

Fig. 1 The genetic structure of IL I7RA gene and the position of Hs02339506_cm TaqMan assay containing primers and probe 
CAGCGATCCAAC-3'; Reverse primer: 5'-GTCTGA GGCAGTCATTGAGGC-3') and for $\beta 2$-microglobulin $(\beta 2 M)$ (Forward primer: 5'-CCTGAATTGCTATGTG TCTGGG-3'; Reverse primer: 5'- TGATGCTGCT TACATGTCTCGA-3'). The mRNA expression was normalized to $\beta 2 M$.

\section{Data analysis}

The Kolmogorov-Smirnov test was implemented for computing normality of tests for continuous variables. We performed Mann-Whitney U non-parametric test to compare the gene expression data between the two groups. Correlation analysis was done by Spearman's rank correlation. Pearson Chi-square test was used to assess the association between the categorical variables.

Furthermore, for checking the effect size odds ratio (OR) with 95\% confidence intervals (95\% CI) was measured. All data were analyzed using IBM SPSS version 21.0 (SPSS, Chicago, IL, USA). In addition, experimental data graphs were designed by GraphPad Prism version 6 (La Jolla, CA, USA). Results with $P$ value less than 0.05 was regarded to be statistically significant.

\section{Results}

\section{Characteristics of study subjects}

The demographic and clinical features of studied subjects are listed in Table 1 . The mean \pm SD age of patients and healthy individuals were $38.10 \pm 10.46$ and $36.60 \pm$ 8.25 years, respectively. There was no statistically significant difference between two groups concerning sex ( $P$ value $=0.37)$ and age $(P$-value $=0.86)$. Patients with AS had higher levels of serum ESR compared to controls ( $P$ value $<0.001$ ).

\section{Analysis of IL17RA CNV}

Based on our results, IL17RA copy number varied from 1 to 4 per diploid genome. As shown in Table 2, $\mathrm{CN}=2$ was the predominant copy count in both groups. One copy number of IL17RA describe gene deletion, while 3 and 4 copy counts are indicative of gene duplication relative to normal 2 copy number. The frequency of two copies of IL17RA was $76.3 \%$ in AS subjects and $85.6 \%$ in the control group. $13.4 \%$ of cases and $6.9 \%$ of controls exhibited 1 copy $(\mathrm{CN}<2)$ of ILI7RA and were remarkably significant. A high copy of $\mathrm{CN}$ seemed to be more in AS patients comparing to healthy subjects (10.3\% vs. $7.6 \%)$, but the difference was not significant. Only 2 patients possessed 4 copies. Based on the results of chi-square test, the overall distribution of the copynumber in the cases compare to control was significantly different $(P$-value $=0.001)$.

Copy numbers were categorized into 3 groups as following: $\mathrm{CN}<1$ (losses), $\mathrm{CN}=2$ (neutral), and $\mathrm{CN}>2$ (gains). As shown in Table 2, the frequency of $\mathrm{CN}$ loss was significantly higher in AS patients (vs. 2 copies OR: $2.18,95 \%$ CI: $(1.38-3.44), P$-value $<0.001)$ in comparison to controls. Although there was no significant difference between the two groups for CNV gain (vs. 2 copies OR:1.53, 95\% CI: (0.963-2.44), $P$-value $=0.071)$. Of note, two copies considered as the reference for estimation of AS risk.

\section{IL17RA mRNA expression level}

To address the association of IL17RA CN to the expression level of this gene, we analyzed IL17RA expression in PBMCs of 68 cases and 53 controls. The expression of IL17RA was higher in all cases compared to controls ( $P$ value $=0.032$, Fold change: AS/Control $=1.17)($ Fig. 2a) . Interestingly, the mRNA level displayed a significant raise in men compared to women. The detailed data are shown in Table 3 and Fig. 2b. The mRNA expression was also assessed by different copy numbers status (Table 4 and Fig. 2c). IL17RA mRNA expression fold change elevated in AS patients in 2 copies group. In contrast, there were no significant mRNA expression changes in $\mathrm{CN}$ loss and $\mathrm{CN}$ gain groups.

\section{Correlation between copy number and mRNA expression of IL17RA with clinical features of AS}

As shown in Table 5, there was no correlation between each of IL17RA copy number categories and clinical characteristics in AS patients. Moreover, IL17RA mRNA expression was not correlated significantly with clinical data (Table 5). However, BASFI and BASMI have higher non-significant effects on IL17RA mRNA expression (Table 5).

Table 2 Frequency distribution of IL17RA copy numbers in cases and controls and estimation of AS risk. (N (\%))

\begin{tabular}{|c|c|c|c|c|}
\hline Copy Number of IL $\mathbf{1 7 R A}$ & AS $(N=455)$ & $\mathrm{HCS}(\mathrm{N}=450)$ & OR $(95 \% \mathrm{Cl})$ & $\boldsymbol{P}$ value \\
\hline$=2$ Copies & $347(76.3 \%)$ & $385(85.6 \%)$ & Ref. & Ref. \\
\hline$<2$ Copies & $61(13.4 \%)$ & $31(6.9 \%)$ & $2.18(1.38-3.44)$ & $<0.001^{\mathrm{a} *}$ \\
\hline$>2$ Copies & $47(10.3 \%)$ & $34(7.6 \%)$ & $1.53(0.963-2.44)$ & $0.071^{\mathrm{a}}$ \\
\hline
\end{tabular}

AS ankylosing spondylitis, $H C s$ healthy controls.

${ }^{a}$ Compared with $=2$ copies

OR Odds ratios, 95\% Cl 95\% confidence interval.

${ }^{*} P$ value $<0.05$ has statistical significance 

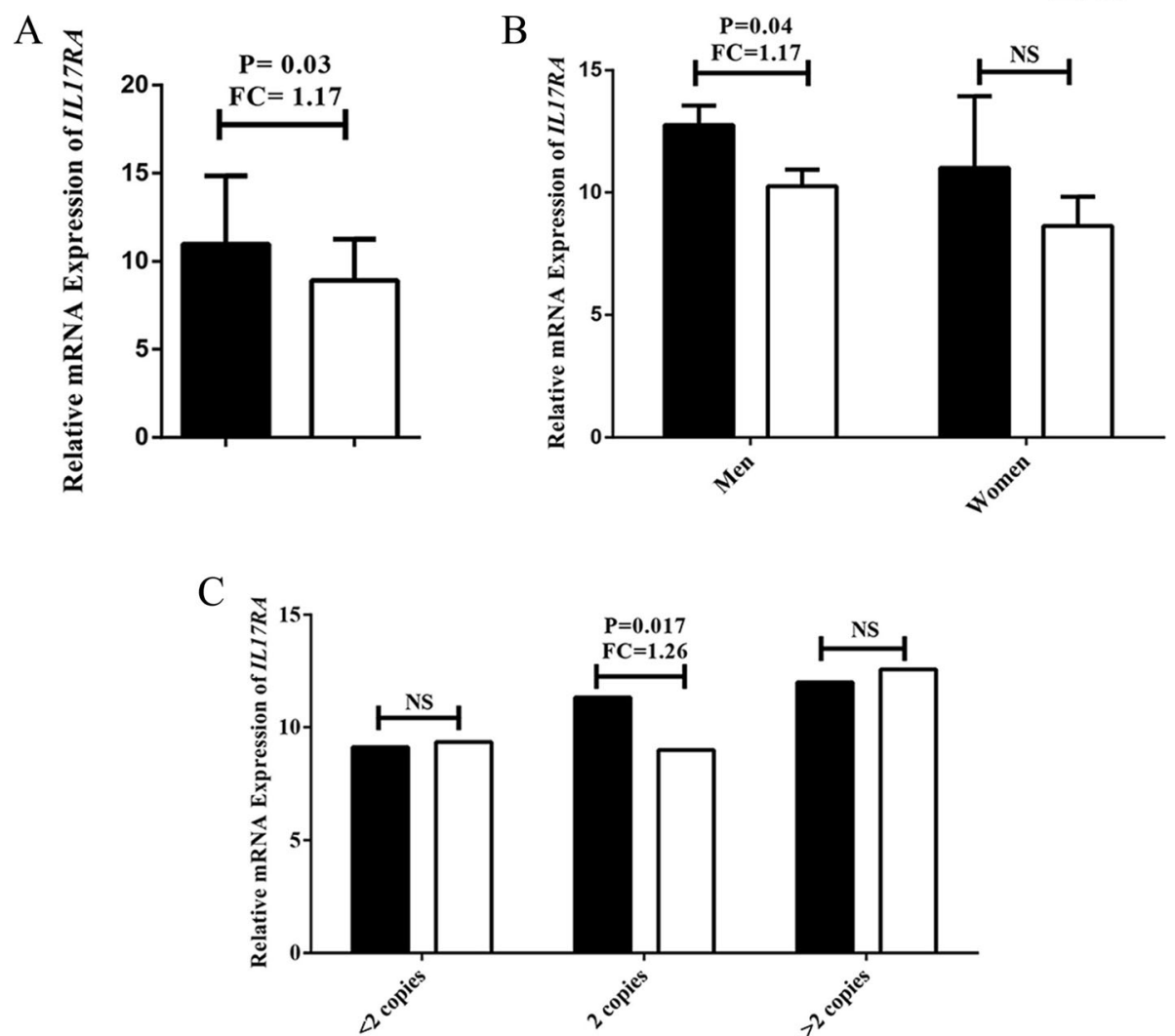

Fig. 2 a Relative gene expression of IL17RA in all AS patients and healthy controls (HC). b Relative gene expression of IL17RA in AS and healthy control groups adjusted by sex. $\mathbf{c}$ Relative gene expression of IL17RA in AS and healthy control groups adjusted by IL17RA copy numbers, NS, not significant

\section{Discussion}

In the present study, the ILI7RA CNVs and mRNA expression levels were evaluated to provide more information about its role in AS disease risk and IL-17A inflammatory pathways.

The fundamental role of IL-17A pathway in AS pathogenesis was identified by the high frequency of Th17 cells and IL-17A expression level in the peripheral blood of AS patients. Several studies showed the importance of IL-17A as a major cytokine that mediates responses in inflammation, infection, and autoimmune diseases through binding to its unique receptor (IL-17RA) and stimulates ACT1 signaling [42]. IL-17RA signaling pathway contributes to the trigger expression of several inflammatory mediators in the active phase of inflammatory diseases [43].
In the recent years, the genome-wide association studies (GWASs) showed the contribution of genes outside of the $\mathrm{MHC}$ region in the risk of $\mathrm{AS}$ and $\mathrm{CNVs}$ received more attention due to their pathophysiological role in autoimmune diseases [44]. A GWAS carried out by Jung et al. has determined 9 candidate genes as $\mathrm{CNVs}$ regions related to AS risk in the Korean population. Among other genes, the only gain in IL17RA was significantly protective against AS, and its influence is suggested in AS development [40]. Recently, Shahba et al. reported the association signal between $B M P 8 A$ copy number variation and susceptibility to AS in Iranian patients [45].

In line with Korean study [40], we showed that having only less than 2 copies of IL17RA gene significantly increased susceptibility to AS. Therefore, it suggests that

Table 3 ILITRA mRNA expression in AS and healthy control groups adjusted by sex (Median \pm Standard Deviation)

\begin{tabular}{lllll}
\hline The mRNA expression level of IL17RA & AS (N=68) & HCs $(\boldsymbol{N}=53)$ & Fold Change (AS/ HC) & $\boldsymbol{P}$-value \\
\hline Overall & $10.73 \pm 5.82$ & $9.19 \pm 4.62$ & 1.17 & $0.032^{*}$ \\
Men & $10.81 \pm 5.81$ & $9.26 \pm 4.75$ & 1.17 & $0.041^{*}$ \\
Women & $9.79 \pm 6.57$ & $8.38 \pm 2.37$ & 1.17 & 0.988 \\
\hline
\end{tabular}

AS ankylosing spondylitis, HCs healthy controls.

${ }^{*} P$-value $<0.05$ has statistical significance 
Table 4 IL 17RA mRNA expression in AS and healthy control groups adjusted by the copy number of IL17RA

\begin{tabular}{lllll}
\hline Copy Number of IL17RA & AS $(\mathrm{N}=68)$ & Control $(\mathrm{N}=53)$ & Fold Change (AS/ HC) & $\boldsymbol{P}$ value \\
\hline $\mathbf{2}$ Copies & $11.33 \pm 6.40$ & $8.99 \pm 4.65$ & 1.26 & $0.017^{*}$ \\
$<\mathbf{2}$ Copies & $9.12 \pm 3.89$ & $9.34 \pm 3.15$ & 0.976 & 0.969 \\
$>\mathbf{2}$ Copies & $12.0 \pm 5.83$ & $12.57 \pm 6.13$ & 0.954 & 0.843 \\
\hline
\end{tabular}

${ }^{*} P$ value $<0.05$ has statistical significance

there is a direct association between low copy number and AS development in both populations. These results proposed that loss of ILITRA is considered as an effective $\mathrm{CNV}$ in AS development in Iranian population. When stratified for sex, no sex bias was detected in $\mathrm{CNVs}$ categories in cases and controls. Additionally, for the first time, we examined IL17RA mRNA expression level to understand how the CNVs of the IL17RA can affect expression of the gene.

Despite the fact, we have observed the loss of gene copy number associated with disease susceptibility, and there was no significant change in mRNA expression level in cases and controls with less than 2 copies. While the increased expression of IL17RA mRNA has been observed in 2 copies group.

Therefore, a lack of significant association of IL17RA CNVs with mRNA expression levels in both groups could be attributed to epigenetic factors and modifications, dysfunction of a transcription factor, and also a specific mutation that may contribute to IL17RA upregulation in AS [46]. DNA methylation, as one of the most epigenetic modifications, has been recognized to influence gene expression [47]. All these strategies can naturally occur in an intuitive phenomenon called genetic compensation. It is a regulatory process that fundamentally responds to the abnormal changes in RNA or protein level [48].

Furthermore, it is expressed that the phenotypic effects of CNVs may have not a direct relationship to gene expression. Some biological mechanisms are proposed to make different phenotypes associated with upregulation and dysregulation of immune responses such as position effect, extra protein-coding domains, and so on $[49,50]$. PBMCs isolation is a less invasive alternative method for measuring expression level as well as copy number of genes compared to the synovial biopsy isolation, therefore, we evaluated the ILI7RA expression in PBMCs. The results that no significant change between the different copy number category of IL17RA gene and its mRNA level might not be true for other tissues, as the expression of this gene varies from tissue to tissue. However, a recent study has studied the genes expression profile in PBMCs of AS patients with inflamed synovial tissue. The authors found a number of immune-associated genes with similar expression change in both PBMCs and synovial tissues. This study suggested that local inflammation could show a reflection in PBMCs alterations [51].

Because of the possible importance of this cytokine in AS and similar conditions, as we expected, the mRNA expression level of IL17RA was significantly higher in all our patients compared to controls. Previous studies indicated increased serum IL-17 level in AS patients showing that this cytokine may play a crucial role with IL-23 in the AS pathogenesis [20, 52, 53]. Following our findings, IL17RA expression was also significantly higher in synoviocytes of RA and psoriatic arthritis (PsA) patients [54]. Reduced production of proinflammatory mediators (e.g., IL-1, IL-6, and different MMPs) along with lessened joint inflammation has been shown in mice with IL17Rdeficient streptococcal cell wall-induced arthritis [55].

Table 5 Associations between mRNA expression and copy number of IL17RA with clinical features of AS

\begin{tabular}{|c|c|c|c|c|c|c|c|}
\hline \multicolumn{8}{|l|}{ AS patients $(\boldsymbol{N}=68)$} \\
\hline \multicolumn{2}{|l|}{ Clinical features } & \multirow{2}{*}{$\begin{array}{l}\mathrm{ESR}, \mathrm{mm} / \mathrm{h} \\
24 \pm 22.09\end{array}$} & \multirow{2}{*}{$\begin{array}{l}\text { Disease } \\
\text { duration, years } \\
9.47 \pm 9.72\end{array}$} & \multirow{2}{*}{$\begin{array}{l}\text { BASDAl } \\
\text { score } \\
5.20 \pm 2.61\end{array}$} & \multirow{2}{*}{$\begin{array}{l}\text { BASFI } \\
\text { score } \\
3.76 \pm \\
2.43\end{array}$} & \multirow{2}{*}{$\begin{array}{l}\text { BASMI } \\
\text { score } \\
3.43 \pm \\
1.69\end{array}$} & \multirow{2}{*}{$\begin{array}{l}\text { ASQol } \\
\text { score } \\
8.29 \pm 5.36\end{array}$} \\
\hline IL17RA & & & & & & & \\
\hline \multirow[t]{2}{*}{ mRNA expression } & $r$ & 0.026 & 0.015 & -0.032 & 0.111 & 0.133 & 0.045 \\
\hline & $P$ & 0.78 & 0.91 & 0.81 & 0.40 & 0.34 & 0.74 \\
\hline \multirow[t]{2}{*}{ Copy number } & $r$ & -0.102 & -0.016 & 0.174 & 0.134 & 0.248 & 0.112 \\
\hline & $P$ & 0.28 & 0.90 & 0.18 & 0.30 & 0.07 & 0.40 \\
\hline \multirow[t]{2}{*}{ mRNA expression } & $\beta(S E)$ & $0.08(0.06)$ & $0.23(0.19)$ & $-0.84(0.69)$ & $1.19(0.83)$ & $-1.2(0.85)$ & $-0.17(0.34)$ \\
\hline & $P$ & 0.19 & 0.25 & 0.23 & 0.16 & 0.17 & 0.62 \\
\hline
\end{tabular}

BASFI bath ankylosing spondylitis functional index, BASDAI bath ankylosing spondylitis disease activity index, BASMI bath ankylosing spondylitis metrology index, $A S Q O L$ ankylosing spondylitis quality of life, $P$ Adjusted $P$-value by Benjamini and Hochberg method to control false discovery rate in multiple testing, $S E$ standard error of coefficient $(\beta), \mathrm{r}$ : Spearman's correlation coefficient 
Therefore, the upregulation of IL17RA could enhance their response to IL-17A and exacerbate inflammation of the joints [43]. In accordance with the previous studies and the current research, it is highly possible to consider an essential role for the IL-17 family with corresponding receptors in ankylosing spondylitis.

The genetic architecture, which is an essential determinant of AS, making it a polygenic complex disease with a more heritable tendency to affect males than females [56, 57]. In our study, increased IL17RA mRNA expression is restricted to male patients, after adjusting by sex. Consistent with our results, Gracey et al. found the upregulation of ILITRA expression in male AS patients [58]. Furthermore, there are not any significant correlation between $\mathrm{CNVs}$ and mRNA expression level with demographic and clinical data of patients in our study.

\section{Conclusion}

In conclusion, regarding the frequency distribution of copy numbers, less than 2 copies of IL17RA were significantly susceptible to AS in this cohort of Iranian patients. Epigenetic mechanisms like DNA methylation, post-transcriptional, and -translational modifications that regulate the expression of the genes may contribute in upregulation of IL17RA mRNA expression in loss of the gene copy number. On the other hand, the significant upregulation mRNA transcript level of IL17RA in all AS patients indicates the critical role of this pathway in the risk of AS. Further researches, especially in the context of functional consequences, seem to be necessary to illuminate the more details of the fundamental role of CNVs with biologic effects.

\section{Supplementary information}

Supplementary information accompanies this paper at https://doi.org/10. 1186/s12881-020-01078-y.

Additional file 1: Supplementary file $\mathbf{1}(. x I s x)$. The data of mRNA expression and copy number of ILITRA in studied patients and controls.

\section{Abbreviations}

CNV: Copy number variation; CD: Crohn's disease; GWAS: Genome-wide association study; GM-CSF: Granulocyte monocyte-colony stimulating factor; G-CSF: Granulocyte-colony stimulating factor; HIV: Human immunodeficiency virus; ILC3: Innate lymphoid cell; IL: Interleukin; MMP: Matrix metalloproteinases; MS: Multiple sclerosis; NKT cells: Natural killer T cells; PSA: Psoriatic arthritis; QoL: Quality of life; RT: Reverse transcription; RA: Rheumatoid arthritis; SNP: Single nucleotide polymorphism; SpA: Spondyloarthritis; SLE: Systemic lupus erythematosus; T1D: Type 1 diabetes; B2M: $\beta 2$-microglobulin;

\section{Acknowledgements}

Not applicable.

\section{Authors' contributions}

HA, SS, SM, and SP: Acquisition of data, drafting the article, analysis and interpretation of data, final approval of the article; EF, MA, and AJ: The conception and design of the study, revising the article critically, interpretation of data, final approval of the article; MM and MHN: The conception and design of the study, revising the article critically, analysis and interpretation of data, final approval of the article. All authors have read and approved the manuscript.

\section{Funding}

This work was financially supported by the grant from the research deputy of Tehran University of Medical Sciences (Grant No. 95-01-30-30949). The

funders had no role in study design, data collection and analysis, decision to publish, or preparation of the manuscript.

\section{Availability of data and materials}

The relevant raw data of this study are available as an Additional file 1.

\section{Ethics approval and consent to participate}

The written informed consent was signed by all members of the case and control groups before enrolling in the study. Moreover, this study was performed based on the Declaration of Helsinki guidelines and was approved by the ethics committee at the Tehran University of Medical Sciences (Approval ID: IR.TUMS.MEDICINE.REC.1398.696).

Consent for publication

Not applicable.

\section{Competing interests}

The authors declare that they have no competing interests.

\section{Author details}

${ }^{1}$ Department of Immunology, School of Medicine, Tehran University of Medical Sciences, Tehran, Iran. ${ }^{2}$ Rheumatology Research Center, Tehran University of Medical Sciences, Tehran, Iran. ${ }^{3}$ Inflammation Research Center, Tehran University of Medical Sciences, Tehran, Iran. ${ }^{4}$ Department of Biostatistics, School of Health, Kermanshah University of Medical Sciences, Kermanshah, Iran. ${ }^{5}$ Molecular Immunology Research Center, Tehran University of Medical Sciences, Tehran, Iran.

Received: 31 January 2020 Accepted: 25 June 2020

Published online: 10 July 2020

\section{References}

1. Tam LS, Gu J, Yu D. Pathogenesis of ankylosing spondylitis. Nat Rev Rheumatol. 2010;6:399-405.

2. Maksymowych WP. Disease modification in ankylosing spondylitis. Nat Rev Rheumatol. 2010;6:75-81.

3. Fallahi S, Mahmoudi M, Nicknam MH, et al. Effect of HLA-B*27 and its subtypes on clinical manifestations and severity of ankylosing spondylitis in Iranian patients. Iran J Allergy Asthma Immunol. 2013;12:321-30.

4. Karami J, Mahmoudi M, Amirzargar A, et al. Promoter hypermethylation of BCL11B gene correlates with downregulation of gene transcription in ankylosing spondylitis patients. Genes Immun. 2017;18:170-5.

5. Aslani S, Mahmoudi M, Garshasbi M, et al. Evaluation of DNMT1 gene expression profile and methylation of its promoter region in patients with ankylosing spondylitis. Clin Rheumatol. 2016;35:2723-31.

6. Vanaki N, Aslani S, Jamshidi A, et al. Role of innate immune system in the pathogenesis of ankylosing spondylitis. Biomed Pharmacother. 2018;105: 130-43.

7. Sieper J, Poddubnyy D. Axial spondyloarthritis. Lancet. 2017;390:73-84

8. Dashti N, Mahmoudi M, Aslani S, et al. HLA-B*27 subtypes and their implications in the pathogenesis of ankylosing spondylitis. Gene. 2018;670: $15-21$.

9. Rezaei R, Mostafaei S, Aslani S, et al. Association study between killer immunoglobulin-like receptor polymorphisms and ankylosing spondylitis disease: an updated meta-analysis. Int J Rheum Dis. 2018;21:1746-55.

10. Almasi S, Aslani S, Poormoghim H, et al. Gene expression profiling of tolllike receptor 4 and 5 in peripheral blood mononuclear cells in rheumatic disorders: Ankylosing spondylitis and rheumatoid arthritis. Iran J Allergy Asthma Immunol. 2016;15:87-92.

11. Ranganathan V, Gracey E, Brown MA, et al. Pathogenesis of ankylosing spondylitis - recent advances and future directions. Nat Rev Rheumatol. 2017; 13:359. 
12. Beringer $A$, Noack $M$, Miossec $P$. IL-17 in chronic inflammation: from discovery to targeting. Trends Mol Med. 2016;22:230-41.

13. Jiang YX, Li PA, Yang SW, et al. Increased chemokine receptor IL-17RA expression is associated with poor survival in gastric cancer patients. Int J Clin Exp Pathol. 2015;8:7002-8.

14. Shen F, Gaffen SL. Structure-function relationships in the IL-17 receptor: implications for signal transduction and therapy. Cytokine. 2008;41:92-104

15. Gaffen SL, Kramer JM, Yu JJ, et al. The IL-17 cytokine family. Vitam Horm. 2006;74:255-82

16. Chang SH, Dong C. Signaling of Interleukin-17 family cytokines in immunity and inflammation. Cell Signal. 2011;23:1069-75.

17. Rezaiemanesh A, Abdolmaleki M, Abdolmohammadi K, et al. Immune cells involved in the pathogenesis of ankylosing spondylitis. Biomed Pharmacother. 2018;100:198-204.

18. Gu C, Wu L, Li X. IL-17 family: cytokines, receptors and signaling. Cytokine. 2013;64:477-85.

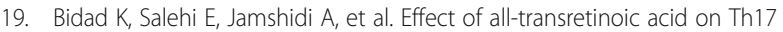
and T regulatory cell subsets in patients with ankylosing spondylitis. J Rheumatol. 2013:40:476-83.

20. Mei Y, Pan F, Gao J, et al. Increased serum IL-17 and IL-23 in the patient with ankylosing spondylitis. Clin Rheumatol. 2011;30:269-73.

21. Jandus C, Bioley G, Rivals JP, et al. Increased numbers of circulating polyfunctional Th17 memory cells in patients with seronegative spondylarthritides. Arthritis Rheum. 2008;58:2307-17.

22. Gaffen $\mathrm{SL}$, Jain $\mathrm{R}$, Garg $A V$, et al. The IL-23-IL-17 immune axis: from mechanisms to therapeutic testing. Nat Rev Immunol. 2014;14:585-600.

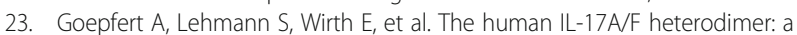
two-faced cytokine with unique receptor recognition properties. Sci Rep. 2017;7:8906

24. Song $X$, Qian Y. IL-17 family cytokines mediated signaling in the pathogenesis of inflammatory diseases. Cell Signal. 2013;25:2335-47.

25. Ishigame $H$. Differential roles of interleukin-17A and $-F$ in host defense against mucoepithelial bacterial infection and allergic responses. Immunity. 2009;30:108-19.

26. Gaffen SL. Structure and signalling in the IL-17 receptor family. Nat Rev Immunol. 2009;9:556-67.

27. Kehlen A, Thiele K, Riemann D, et al. Expression, modulation and signalling of IL-17 receptor in fibroblast-like synoviocytes of patients with rheumatoid arthritis. Clin Exp Immunol. 2002;127:539-46.

28. Abdolmohammadi $\mathrm{K}$, Pakdel FD, Aghaei $\mathrm{H}$, et al. Ankylosing spondylitis and mesenchymal stromal/stem cell therapy: a new therapeutic approach. Biomed Pharmacother. 2019;109:1196-205.

29. Soleimanifar N, Amirzargar AA, Mahmoudi M, et al. Study of programmed cell death 1 (PDCD1) gene polymorphims in Iranian patients with ankylosing spondylitis. Inflammation. 2011;34:707-12.

30. Daryabor G, Mahmoudi M, Jamshidi A, et al. Determination of IL-23 receptor gene polymorphism in Iranian patients with ankylosing spondylitis. Eur Cytokine Netw. 2014;25:24-9.

31. Mahmoudi M, Jamshidi AR, Amirzargar AA, et al. Association between endoplasmic reticulum aminopeptidase-1 (ERAP-1) and susceptibility to ankylosing spondylitis in Iran. Iran J Allergy Asthma Immunol. 2012;11:294300.

32. Momenzadeh $\mathrm{P}$, Mahmoudi M, Beigy M, et al. Determination of IL1 R2, ANTXR2, CARD9, and SNAPC4 single nucleotide polymorphisms in Iranian patients with ankylosing spondylitis. Rheumatol Int. 2016;36:429-35.

33. Vidal-Castineira JR, Lopez-Vazquez A, Diaz-Pena R, et al. A single nucleotide polymorphism in the II17ra promoter is associated with functional severity of Ankylosing spondylitis. PLoS One. 2016;11:e0158905.

34. Usher CL, McCarroll SA. Complex and multi-allelic copy number variation in human disease. Brief Funct Genomics. 2015;14:329-38.

35. Redon $\mathrm{R}$, Ishikawa $\mathrm{S}$, Fitch KR, et al. Global variation in copy number in the human genome. Nature. 2006:444:444-54.

36. Stankiewicz P, Lupski JR. Structural variation in the human genome and its role in disease. Annu Rev Med. 2010;61:437-55.

37. Gamazon ER, Stranger BE. The impact of human copy number variation on gene expression. Briefings Funct Genomics. 2015;14:352-7.

38. Bigagli E, De Filippo C, Castagnini C, et al. DNA copy number alterations, gene expression changes and disease-free survival in patients with colorectal cancer: a 10 year follow-up. Cell Oncol (Dordr). 2016;39:545-58.

39. Grayson BL, Smith ME, Thomas JW, et al. Genome-wide analysis of copy number variation in type 1 diabetes. PLoS One. 2010;5:e15393.
40. Jung $\mathrm{SH}, \mathrm{Yim} \mathrm{SH}, \mathrm{Hu} \mathrm{HJ}$, et al. Genome-wide copy number variation analysis identifies deletion variants associated with ankylosing spondylitis. Arthritis Rheumatol. 2014;66:2103-12.

41. Zochling J. Measures of symptoms and disease status in ankylosing spondylitis: Ankylosing Spondylitis Disease Activity Score (ASDAS), Ankylosing Spondylitis Quality of Life Scale (ASQoL), Bath Ankylosing Spondylitis Disease Activity Index (BASDAI), Bath Ankylosing Spondylitis Functional Index (BASFI), Bath Ankylosing Spondylitis Global Score (BAS-G), Bath Ankylosing Spondylitis Metrology Index (BASMI), Dougados Functional Index (DFI), and Health Assessment Questionnaire for the Spondylarthropathies (HAQ-S). Arthritis Care Res (Hoboken). 2011;63(Suppl 11):S47-58.

42. Qian Y, Liu C, Hartupee J, et al. The adaptor Act1 is required for interleukin 17-dependent signaling associated with autoimmune and inflammatory disease. Nat Immunol. 2007:8:247-56.

43. Sadik CD, Kim ND, Alekseeva E, et al. IL-17RA signaling amplifies antibodyinduced arthritis. PLoS One. 2011;6:e26342.

44. Olsson LM, Holmdahl R. Copy number variation in autoimmunity-importance hidden in complexity? Eur J Immunol. 2012;42:1969-76.

45. Shahba S, Jafari Shakib R, Jamshidi A, et al. Association study of copy number variation in BMP8A gene with the risk of ankylosing spondylitis in Iranian population. J Cell Biochem. 2018.

46. Myhre S, Lingjaerde OC, Hennessy BT, et al. Influence of DNA copy number and mRNA levels on the expression of breast cancer related proteins. Mol Oncol. 2013;7:704-18.

47. Mahmoudi M, Aslani S, Nicknam MH, et al. New insights toward the pathogenesis of ankylosing spondylitis; genetic variations and epigenetic modifications. Mod Rheumatol. 2017;27:198-209.

48. Veitia RA, Bottani S, Birchler JA. Gene dosage effects: nonlinearities, genetic interactions, and dosage compensation. Trends Genet. 2013;29:385-93.

49. Hollox EJ, Hoh BP. Human gene copy number variation and infectious disease. Hum Genet. 2014;133:1217-33.

50. Henrichsen CN, Chaignat E, Reymond A. Copy number variants, diseases and gene expression. Hum Mol Genet. 2009;18:R1-8.

51. Thomas GP, Duan R, Pettit AR, et al. Expression profiling in spondyloarthropathy synovial biopsies highlights changes in expression of inflammatory genes in conjunction with tissue remodelling genes. BMC Musculoskelet Disord. 2013;14:354.

52. Wang $X$, Lin Z, Wei Q, et al. Expression of IL-23 and IL-17 and effect of IL-23 on IL-17 production in ankylosing spondylitis. Rheumatol Int. 2009;29:13437.

53. Chen W-S, Chang Y-S, Lin K-C, et al. Association of serum interleukin-17 and interleukin-23 levels with disease activity in Chinese patients with ankylosing spondylitis. J Chinese Med Assoc. 2012;75:303-8.

54. Raychaudhuri SP, Raychaudhuri SK, Genovese MC. IL-17 receptor and its functional significance in psoriatic arthritis. Mol Cell Biochem. 2012;359:41929.

55. Koenders MI, Kolls JK, Oppers-Walgreen B, et al. Interleukin-17 receptor deficiency results in impaired synovial expression of interleukin-1 and matrix metalloproteinases 3, 9, and 13 and prevents cartilage destruction during chronic reactivated streptococcal cell wall-induced arthritis. Arthritis Rheumatism. 2005;52:3239-47.

56. Lee W, Reveille JD, Davis JC, et al. Are there gender differences in severity of ankylosing spondylitis? Results from the PSOAS cohort. Ann Rheum Dis. 2007;66:633-8.

57. Shahlaee A, Mahmoudi M, Nicknam MH, et al. Gender differences in Iranian patients with ankylosing spondylitis. Clin Rheumatol. 2015;34:285-93.

58. Gracey E, Yao Y, Green B, et al. Sexual dimorphism in the Th17 signature of Ankylosing spondylitis. Arthritis Rheumatol. 2016;68:679-89.

\section{Publisher's Note}

Springer Nature remains neutral with regard to jurisdictional claims in published maps and institutional affiliations. 